\title{
ANÁLISE DE MANIFESTAÇÕES PATOLÓGICAS EM UMA EDIFICAÇÃO ESCOLAR EM ITAJAÍ/SC
}

\author{
RAIMUNDO TRIERWEILER, BEATRIZ \\ Acadêmica em Engenharia Civil \\ Universidade do Vale do Itajaí \\ Santa Catarina; Brasil \\ bia_trierweiler@hotmail.com
}

\author{
DAL MOLIM, NICOLE THAIS \\ Acadêmica em Engenharia Civil \\ Universidade do Vale do Itajaí \\ Santa Catarina; Brasil \\ nicoledm4@gmail.com
}

\author{
SILVA DOS SANTOS, JÉSSICA \\ Acadêmica em Engenharia Civil \\ Universidade do Vale do Itajaí \\ Santa Catarina; Brasil \\ jessica.andreza.silva@hotmail.com \\ VENANCIO, CAROLINE \\ Engenheira Civil, phD \\ Universidade do Vale do Itajaí \\ Santa Catarina; Brasil \\ caroline.venancio@univali.br
}

\section{RESUMO}

Este trabalho tem como objetivo identificar as principais manifestações patológicas existentes, suas causas e origem prováveis, em uma edificação escolar localizada na cidade de Itajaí - SC. O documento aponta as possíveis irregularidades construtivas e manifestações patológicas encontradas, detalhando e descrevendo os problemas identificados e investigações quanto às suas possíveis causas e origem. As inspeções procedem ao diagnóstico das manifestações patológicas da edificação, que interferem no estado de utilização do imóvel. Vários são os aspectos a serem verificados, como desempenho, vida útil, utilização e segurança. A partir dos registros fotográficos foi possível catalogar as manifestações patológicas, seus mecanismos de formação e sugerir possíveis estratégias de correção para cada caso. A principal incidência de manifestações patológicas encontradas foram fissuras, que em sua maioria, surgiram em decorrência do recalque diferencial. Esta análise foi de extrema relevância para a indústria da construção civil, uma vez que permite a avaliação e o conhecimento das possíveis causas e danos, para uma correta apuração de mecanismos de recuperação, apropriados para cada tipo de manifestação patológica.

Palavras-chave: laudo técnico, manifestações patológicas, edificação escolar.

\section{ABSTRACT}

This work analysis aims to identify the main existing pathological manifestations, their probable causes and origin, in a school building located in the city of Itajaí - SC. The document points out the possible constructive irregularities and pathological manifestations found, detailing and describing the identified problems and investigations as to their possible causes and origin. The inspections proceed to the diagnosis of the pathological manifestations of the building, that interfere in the state of use of the property. There are several aspects to check, such as performance, life, use and safety. From photographic records, it was possible to catalog the pathological manifestations, their mechanisms of formation and suggest possible correction strategies for each case. The main incidence of pathological manifestations found were fissures, which mostly arose as a result of differential movements. This analysis was extremely important to the construction, as it allows the assessment and knowledge of possible causes and damages, for a correct investigation of recovery mechanisms, appropriate for each type of pathological manifestation.

Keywords: technical report, pathological manifestations, school building.

\section{INTRODUÇÃO}

A referida edificação escolar, objeto de estudo deste trabalho foi inaugurada em setembro de 2004 e atualmente comporta alunos desde a pré-escola ao $9^{\circ}$ ano. A abordagem desta pesquisa é direcionada, principalmente, para a área externa da edificação, uma vez que a maioria das manifestações patológicas foram encontradas nestas áreas.

As manifestações patológicas se caracterizam como expressões resultantes de um mecanismo de degradação, deste modo podem ser entendidas por sintomas que uma edificação pode apresentar ao longo de sua vida útil. Comumente, tais anomalias podem ser detectadas visualmente, uma vez que estão diretamente relacionadas à sua causa, da mesma forma que sua origem, pode estar diretamente ligada à "raiz" do problema. Neste contexto, vários são os fatores e conceitos 
associados ao surgimento de cada tipo de manifestação, que podem trazer desconforto ao usuário em vários aspectos, ligados ou não à falta de manutenção e requisitos de segurança. Com base em bibliografias e na detecção das manifestações patológicas catalogadas neste documento, inspeção fotográfica, análise visual e anamnese realizadas, tornase possível fazer um prognóstico de suas possíveis causas e origens.

\section{HISTÓRICO DA EDIFICAÇÃO E ANAMNESE}

\subsection{Características gerais}

As informações referentes ao histórico e anamnese foram obtidas através de entrevistas com funcionários da edificação educacional e uma das autoras desta pesquisa estudou nesta escola durante nove anos. Segundo os relatos dos funcionários, o local foi inaugurado para atender uma demanda de estudantes que crescia em demasia na região, além disso, ao longo dos anos a escola sofreu por reformas no ano de 2014, onde sua estrutura foi reforçada, instalações elétricas e hidráulicas foram substituídas e adicionadas devido à instalação de novos chuveiros, torneiras, etc. As rampas de acesso foram recuperadas e a edifcação totalmente repintada. Em todo o perimetro da escola havia um talude, de aproximadamente $1,50 \mathrm{~m}$ de altura em contato com as fachadas externas da edificação. Após a vistoria no local, se constatou que não existe mais o talude e há mau cheiro abaixo da edificação - verificou-se que ali há tubulações que desaguam diretamente no solo, o que pode justificar o mau cheiro encontrado nesta região.

\section{VISTORIA}

\subsection{Procedimentos de inspeção}

Para a elaboração desta análise das manifestações patológicas, foi necessário realizar uma visita à escola com o intuito de catalogar e detectar as manifestações patológicas existentes na edificação. A visita foi realizada no período da tarde, com o tempo predominantemente ensolarado e o método de vistoria utilizado para detecção das manifestações patológicas, foi a inspeção fotográfica e visual, por meio de aparelho de telefone celular e régua para aferição da espessura das aberturas.

\subsection{Identificação e descrição das manifestações patológicas}

Neste tópico aborda-se uma síntese bibliográfica quanto aos tipos de manifestações predominantes na edificação. Deste modo, a fim de facilitar a compreensão quanto aos conceitos que norteiam estas manifestações, fez-se a separação de acordo com o maior grau de incidência, em sequência:

\subsubsection{Fissuras}

A existência de fissuras em estruturas de concreto armado é um problema de grande importância, não somente do ponto de vista econômico, ao originar gastos de recuperação e diminuir a vida útil das edificações, mas também por atingir o usuário sob o ponto de vista de conformo, salubridade e satisfação psicológica dentro da edificação. (MOLIN, 1988).

Além disso, outra perspectiva que deve ser muito bem analisada na presença de fissuras em elementos estruturais de concreto armado, é sua correlação com o aviso prévio de problemas estruturais sérios na edificação, além de comprometimento do desempenho de serviço da obra (requisitos que atendem a NBR 15575).

As fissuras podem ser classificadas quanto a sua espessura ou atividade, podendo ser ativas ou passivas. (DUARTE, 1998). De forma simples, as fissuras ativas podem ser compreendidas como fissuras que apresentam variação linear, ou seja, se movimentam, por exemplo, fissuras ocasionadas por variação térmica. Já as fissuras passivas encontram-se estabilizadas, ou seja, não apresentam nenhuma variação ao longo do tempo. (ZANZARINI, 2016). As fissuras podem ser causadas por vários fatores, entre eles a retração hidráulica, variação de temperatura, flexão, cisalhamento, torção, compressão, tração, punção e umidade.

\subsubsection{Umidade}

As ações da água, nas suas diversas formas, podem gerar patologia em edificações. A umidade representa um dos problemas mais difíceis de serem solucionados na construção civil. Os problemas gerados pela umidade causam desconforto aos usuários, podendo afetar também sua saúde, possuem rápida degradação, causam prejuízo financeiro e de caráter funcional da edificação, também causando danos a equipamentos e objetos que estão no interior da obra. 
Os fatores que podem causar umidade em uma obra são diversos, podendo ser trazidos por capilaridade, por chuva, resultante de vazamentos hidráulicos, pelo fenômeno de condensação, e também pode ter acontecido durante a construção. A umidade age como um meio para que grande parte dos problemas em construções ocorra. É o fator essencial para que aconteçam eflorescências, corrosão, mofo, bolores, perda de pintura, de rebocos e até a causa de acidentes estruturais.

\subsubsection{Pintura}

Em revestimentos de pintura, a patologia pode aparecer após sua aplicação ou durante a sua utilização, e está relacionada à interface do filme com o substrato ou a própria película da pintura. Esses problemas podem ser causados pela escolha inadequada da tinta de acordo com sua exposição ou incompatibilidade com o substrato; condições meteorológicas inadequadas por temperatura; umidade muito alta ou muito baixa e ventos fortes. Pode ser causada também pela ausência de preparo do substrato ou preparo insuficiente; o substrato pode não apresentar estabilidade; excesso de umidade no substrato. Os defeitos na tinta também podem ocorrer pela sua diluição excessiva ou formulação inadequada. A formulação inadequada da tinta pode causar problemas como descoloração, enrugamento, fissuração e pulverulência.

Deve-se sempre haver a compatibilização entre os materiais e sistemas, e realizada uma limpeza na superfície a ser aplicada a tinta para que não haja manifestações patológicas. Em questão de aderência, as manifestações mais comuns são o empolamento, descamação, destacamento e destacamento entre camadas.

\subsubsection{Rachaduras}

As rachaduras, de acordo com Zanzarini (2016) são classificadas como aberturas entre 1,5 e 5,0mm e são indicativos claros de que a estrutura está sob tensão, portanto rachaduras de qualquer natureza devem ser avaliadas tecnicamente, pois trata-se de problemas estruturais severos.

\subsubsection{Fendas}

Zanzarini (2016) classifica fendas como aberturas de maior grau (5,0 a 10,0mm). É caracterizado como fenda o estado em que um determinado objeto ou parte dele apresentam uma abertura superior à de uma rachadura, suas causas nem sempre são visíveis como, por exemplo, no caso de solapamento do subsolo, além disso, podem se manifestar de forma instantânea e assim ocasionar acidentes (SANTOS, 2019).

\subsubsection{Corrosão}

Nos elementos estruturais onde o aço já tenha sofrido corrosão, ocorre um aumento de volume de até oito vezes, este aumento gera tensões, às quais o concreto não resiste, formando-se assim as fissuras. As armaduras mais próximas à superfície do elemento estrutural ficam mais expostas à ação dos agentes externos, provocando maior corrosão nestes pontos e posteriormente, o desplacamento do concreto. (GONÇALVES, 2015).

\section{INSPEÇÃo FOTOGRÁFICA E AVALIAÇÃo DE POSSÍVEIS CAUSAS E ORIGENS}

$\mathrm{Na}$ vistoria realizada, foram encontradas diversas ocorrências de problemas patológicos, que se repetem em vários locais da edificação. Elencam-se neste tópico as principais manifestações patológicas observadas.

\subsection{Fissuras}

a. Caso 1: Existe uma abertura alongada que, em sua maioria, caracteriza-se com uma fissura, que segue como uma linha retilínea contornando as paredes externas, conforme Figura 1. 


\section{CBPAT 2020 \\ CONGRESSO BRASILEIRO DE PATOLOGIA DAS CONSTRUÇÕES \\ DE 15 A 17 DE ABRIL | FORTALEZA - CE}

ISBN 978-65-86819-05-2

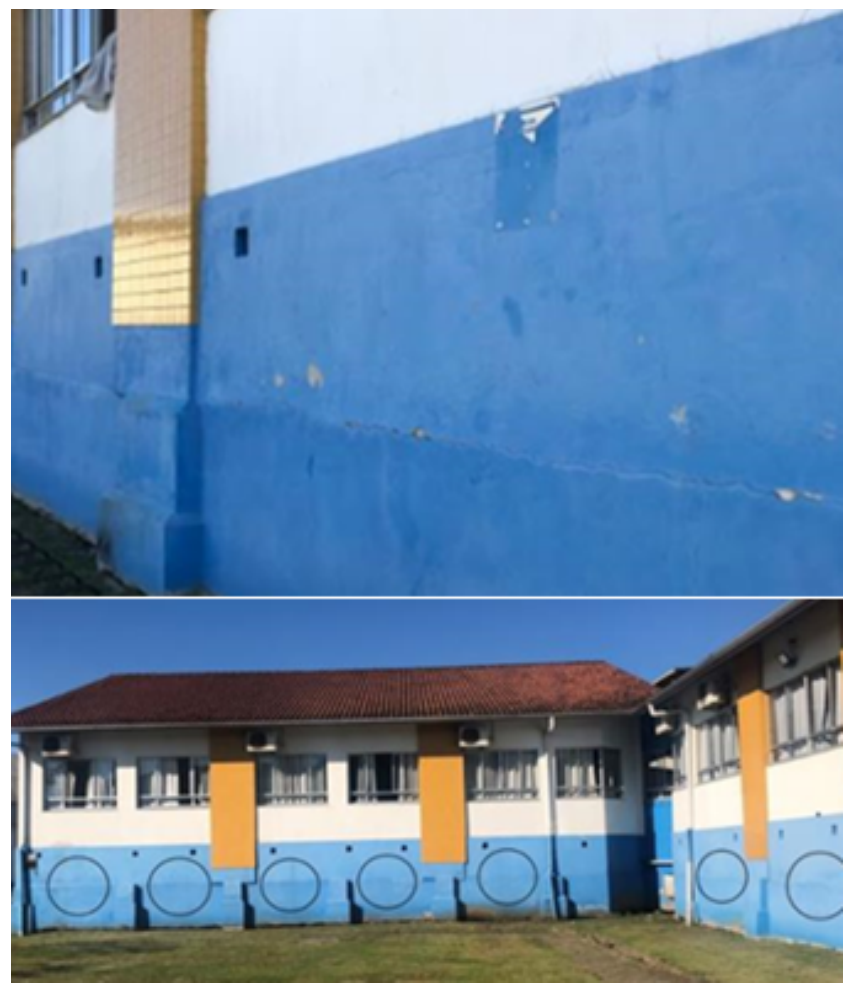

Figura 1: Fachadas com incidência de fissura contínua

Conforme descrito na Anamnese, existia um talude de aproximadamente $1,50 \mathrm{~m}$ de altura que contornava toda a escola. Esse talude servia como uma barreira de estabilidade para a estrutura, uma vez que, após a retirada do mesmo, a fundação demonstrou sinais visíveis de recalque, que consequentemente, causou a fissura progressiva em quase todo o contorno. A origem do recalque se deu por erro de dimensionamento (projeto e execução) da fundação e da estrutura. Além de estar relacionada com vazamentos de água - de tubulações que passam no interior da edificação, que causam erosão do solo e, consequentemente, transporte do mesmo, gerando um "vazio", por onde uma parte da fundação cede.

Dessa forma, a remoção do talude, além de demonstrar visualmente o processo que já existia, intensificou o processo de desestabilização.

b. Caso 2: A Figura 2 apresenta fissuras devido ao cisalhamento e um corrimão metálico desprendido da estrutura devido ao desplacamento do concreto e das fissuras originadas no local.

A manifestação patológica encontra-se na subida da rampa que dá acesso aos fundos da escola, onde se encontra o início do corrimão metálico. Como nota-se na Figura 2, há fissuras e trincas. A fissura que aparece próxima ao apoio da subida da rampa em um ângulo de $45^{\circ}$ foi causada devido à alta porosidade do concreto aliada a erros de execução da rampa ausência ou montagem inadequada das armaduras. Dessa forma, esses dois fatores causaram "brechas" na estrutura, ocasionando a infiltração da água, o que intensificou o desplacamento do material e fissuramento por cisalhamento. 


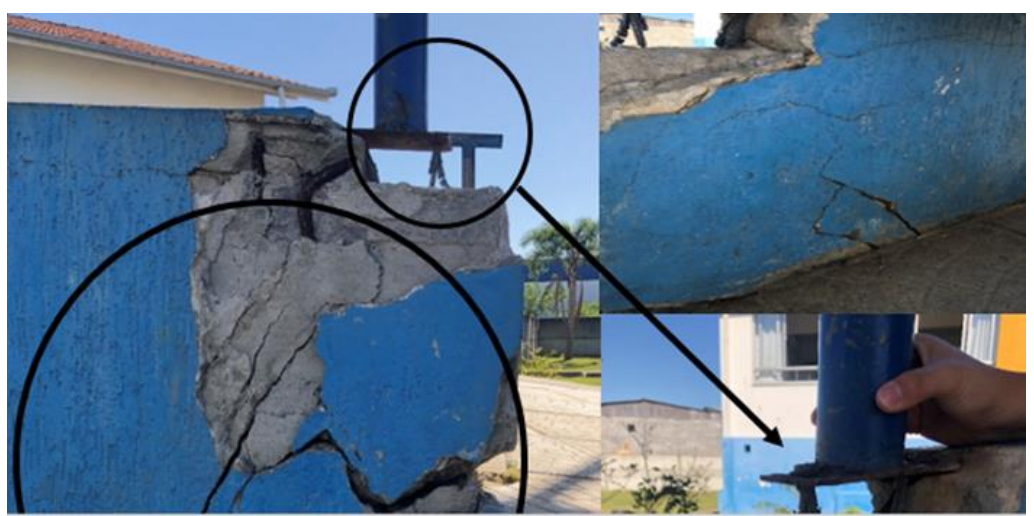

Figura 2: Fissuras de desplacamento

Portanto, destaca-se como principal causa desta manifestação, a má qualidade do concreto e erros de dimensionamento estrutural, visto que no local em que ocorreu disgregação do concreto, há falta de armadura transversal. A má execução da rampa causou infiltração de água, o que intensificou o desplacamento do material e a fissuração por cisalhamento. Já no corrimão, é possível perceber a sua má fixação, dada por chumbadores inadequados e devido ao desplacamento do concreto, como também é possível perceber na Figura 2.

c. Caso 3: Há uma fissura vertical alongada na superfície central da parede externa da edificação. Quanto à sua geometria, a abertura inicia-se verticalmente no centro e percorre a parede em $45^{\circ}$ em direção aos cantos das janelas, conforme Figura 3.

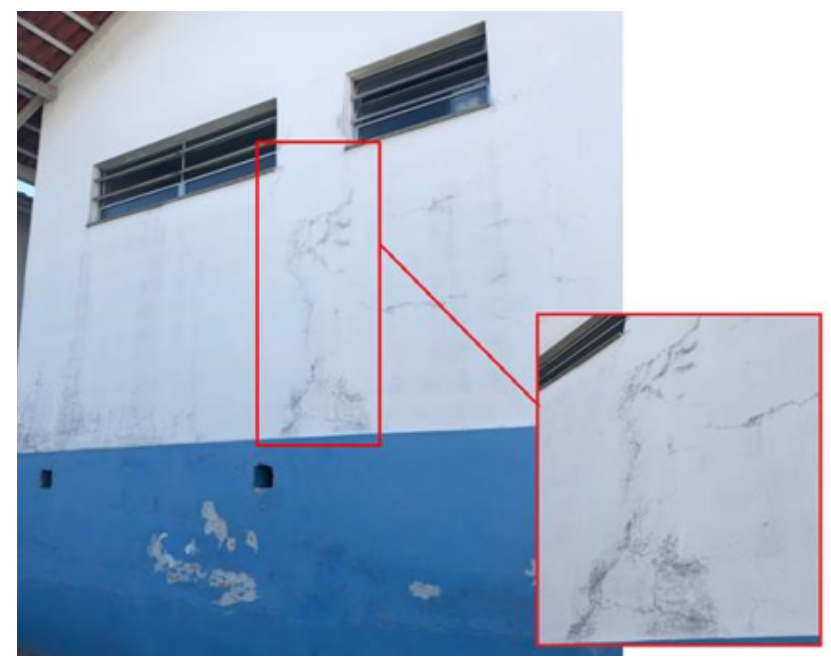

Figura 3: Fissura central em parede externa

A fissura foi causada por abertura na parede posterior à execução da mesma, relacionada à passagem da tubulação de ar condicionado.

d. Casos 4 e 5: De acordo com sua geometria e localização, conforme Figura 4 e 5, sugere-se que as fissuras apresentadas têm origem na movimentação do terreno e consequentemente recalque diferencial neste trecho da edificação. Essas manifestações são causadas pela descontinuidade da base em que a edificação está sustentada, causando "quebra" do elemento quando suas bases se apresentam desniveladas. A origem do recalque diferencial se encontra em erros de projeto e execução da estrutura e da fundação da edificação. 


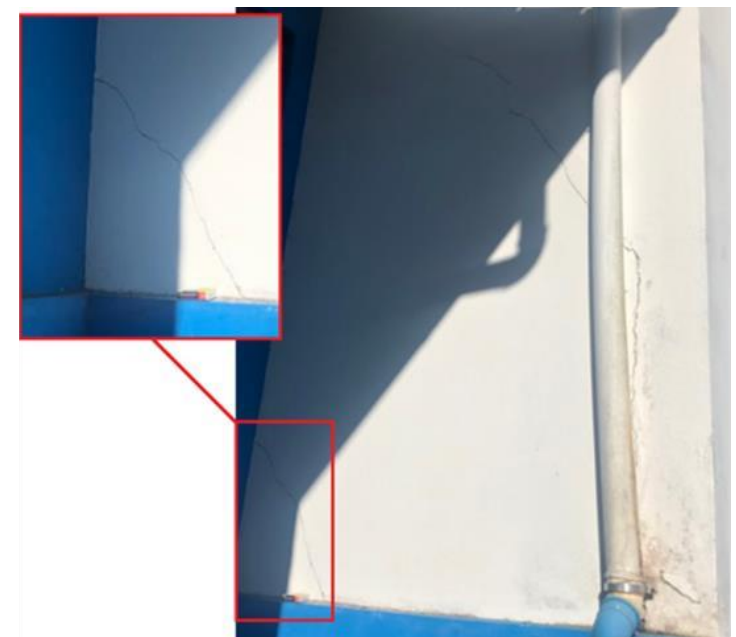

Figura 4: Fissuração longitudinal seguida de inclinada

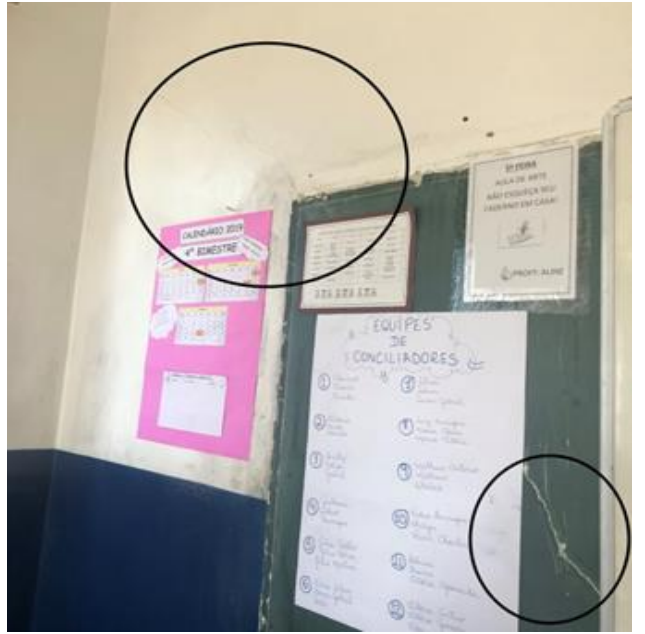

Figura 5: Fissura em $45^{\circ}$ na sala de aula

\subsection{Umidade}

a. Caso 1: A Figura 6 apresenta emboloramento na parte inferior da parede, próximo à grama.

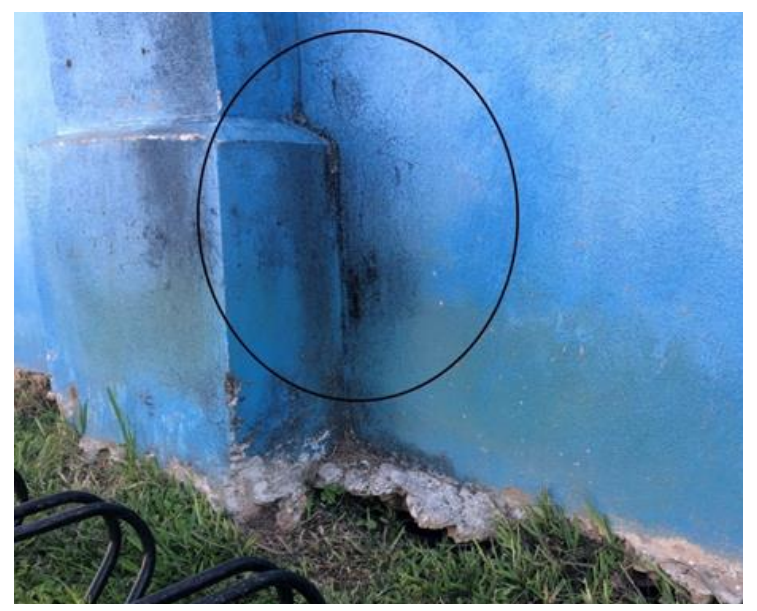

Figura 6: Fachada externa com umidade

A possível causa do aparecimento do bolor está diretamente ligada a fonte de umidade existente no local, além disso, através da inspeção, foi detectado que a região recebe pouca incidência de luz solar. Regiões próximas à grama também são favoráveis ao aparecimento de fungos e microrganismos. A origem desta umidade pode estar ligada a existência de microfissuras que facilitam a infiltração de água, deixando o ambiente exposto à umidade.

b. Caso 2: A Figura 7 apresenta uma mancha de umidade na parede, junto à uma fissura de $45^{\circ}$. 

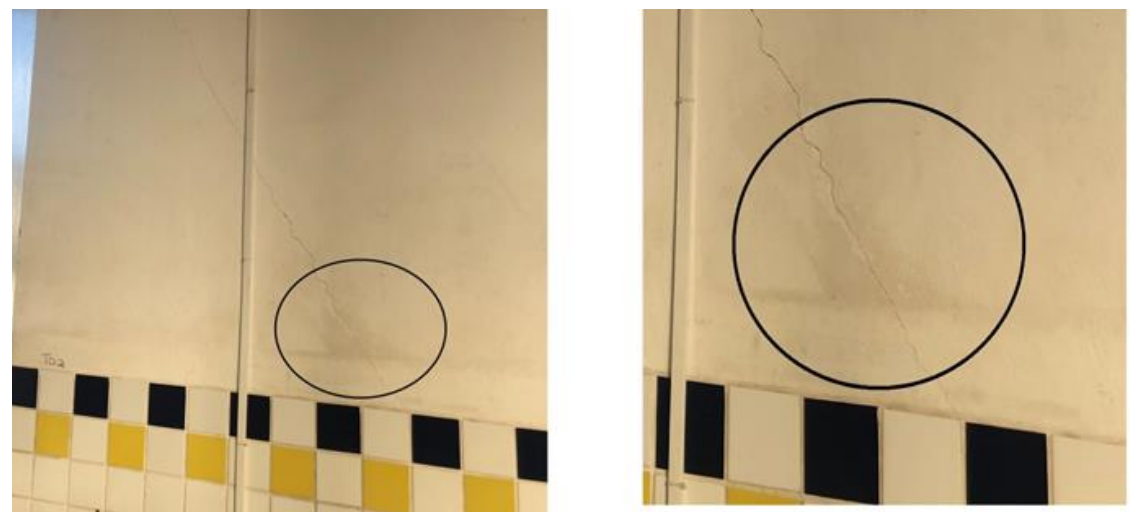

Figura 7: Umidade próxima à fissura

Essa mancha de umidade foi causada por pela infiltração de água, devido à fissura, que permite que a água percole com mais facilidade. A origem da fissura pode estar diretamente ligada ao recalque diferencial que a estrutura está sofrendo, evidenciada pelo posicionamento em $45^{\circ}$.

c. Caso 3: A Figura 9 apresenta manchas de umidade e descascamento da tinta na parede no bebedouro da escola.

A parede em questão localiza-se no segundo pavimento e é a mesma onde o bebedouro de água está apoiado. Devido à passagem de canalização de água, ocorre a umidade acidental, justificando a mancha presente nesta região. Esta mancha foi causada pelo vazamento de água, que pode ter sido originado por reformas feitas na escola, as quais mudaram muitas das instalações hidráulicas existentes para novas, neste caso, podendo ser até mesmo por má vedação entre canos.

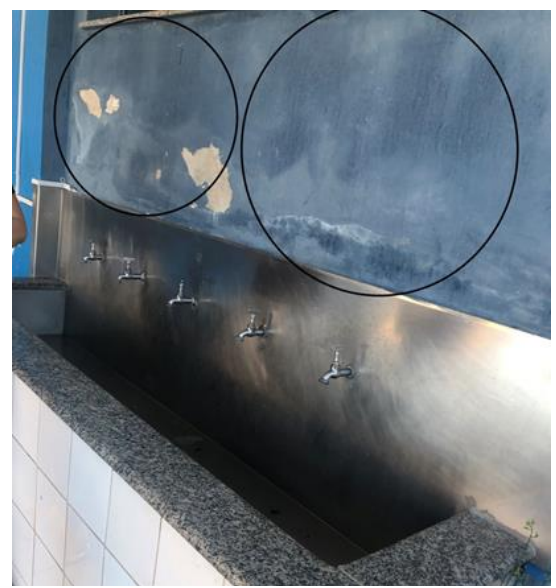

Figura 9: Parede do bebedouro com problema de infiltração de umidade.

\subsection{Pintura}

a. Caso 1: A Figura 10 apresenta dois tipos de manifestações patológicas, que são: biodegradação da pintura e descascamento. 


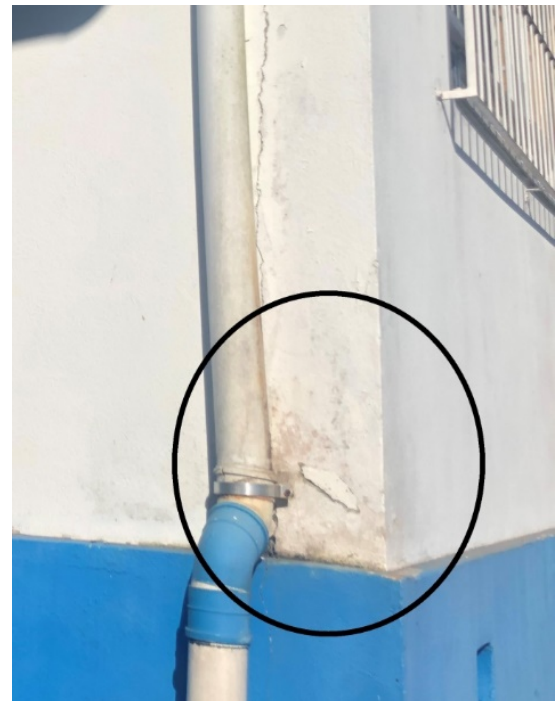

Figura 10: Parede com biodegradação e descascamento

As manifestações patológicas encontram-se exatamente ao lado do cano de água, principalmente na parte em que o mesmo foi fixado, causando fissuras que absorveram água. A biodegradação ocorreu pela proximidade da parede à uma fonte de umidade, que é o cano presente no local, que vem da calha.

Com relação ao descascamento, este foi causado devido a um mau preparo da base e má compatibilização entre fundo e tinta, sendo agravado pela umidade local.

b. Caso 2: Mostra-se na Figura 11, bolhas ao longo do teto do banheiro feminino da escola.

Manifestações patológicas como bolhas estão relacionadas à aderência da tinta à superfície. Quando foi realizada nova pintura, durante a reforma, haviam substâncias/partículas na superfície existente - por se tratar de um ambiente úmido, possivelmente mofo, originado da umidade e falta de incidência solar, o que prejudicou a aderência entre nova tinta e superfície, fazendo com que a umidade absorvida, ao evaporar, empurrasse a película de tinta, formando as bolhas.
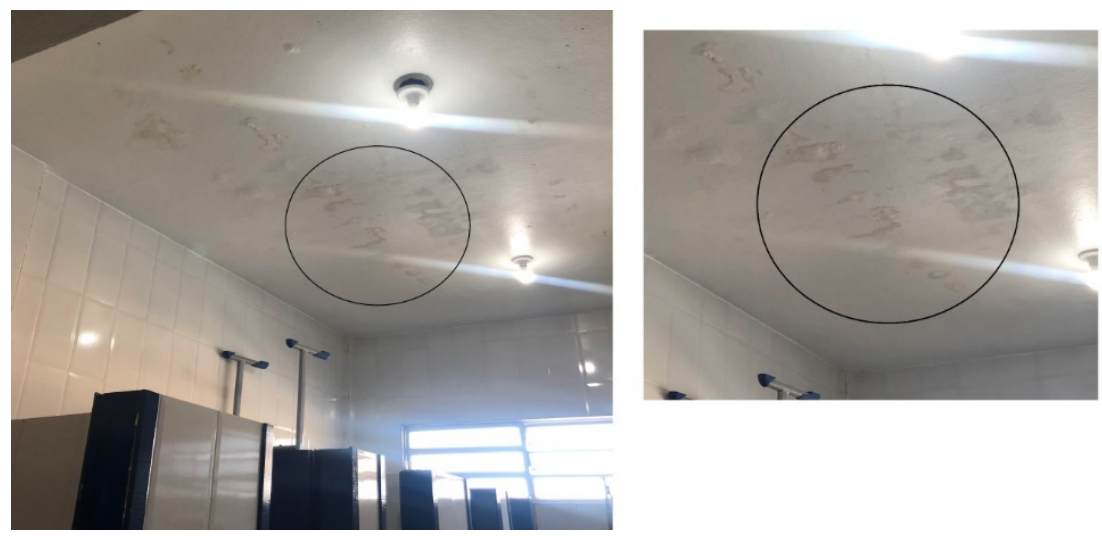

Figura 11: Bolhas no teto do banheiro

\subsection{Fendas}

Conforme Figura 12, observa-se a ocorrência de fendas horizontais, que causam a separação da estrutura com o chão e acompanham aproximadamente metade das fachadas da escola. 


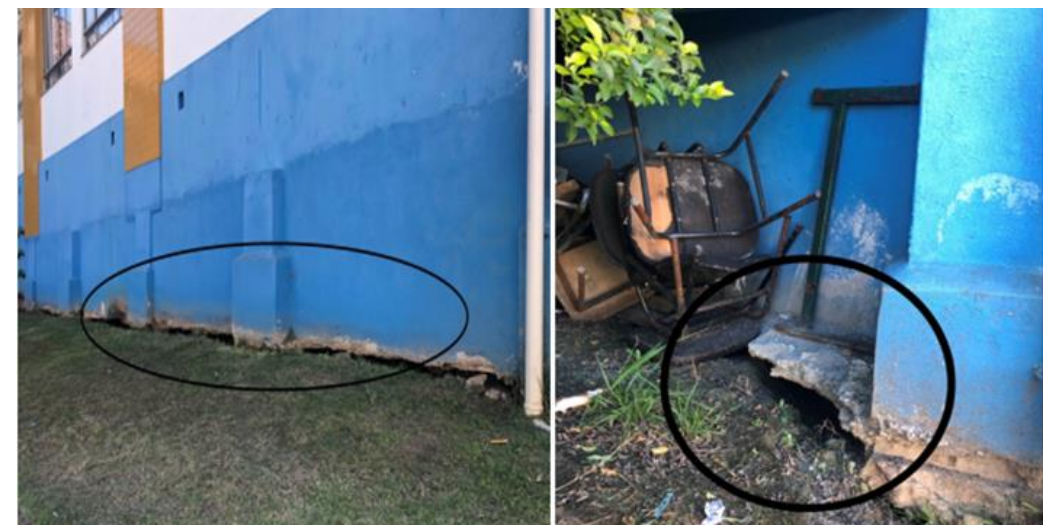

Figura 12: Fenda horizontal

$\mathrm{Na}$ edificação, podem-se identificar diversas manifestações patológicas causadas por recalque da estrutura. E conforme já descrito, a origem do mesmo pode estar relacionada a vazamentos de água - de tubulações que passam no interior da edificação, que causam erosão do solo e, consequentemente, transporte do mesmo, gerando um "vazio", por onde a fundação cede.

\subsection{Rachaduras}

a. Caso 1: Conforme já mencionado, foi observada uma abertura alongada que cerca a maioria das paredes externas da edificação, se apresentando de forma mais acentuada, em forma de rachadura na parte inferior da rampa. Nessa região, ocorreu ruptura do elemento, separando em duas partes com aberturas que variam entre 3 e $5,5 \mathrm{~cm}$ aproximadamente, o que chega a caracterizar a abertura com Fenda, pronunciadas, profundas e acentuadas, podendo ser notadas nas Figuras 13 e 14.

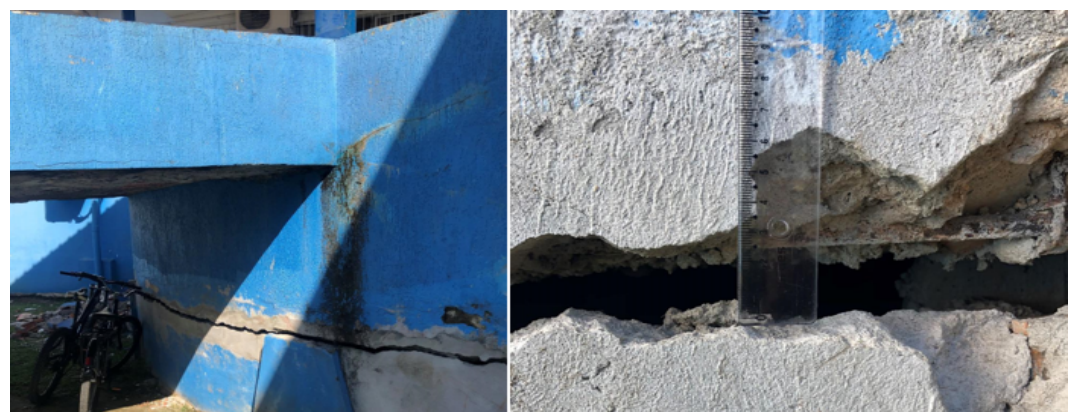

Figura 13: Rachadura abaixo da rampa
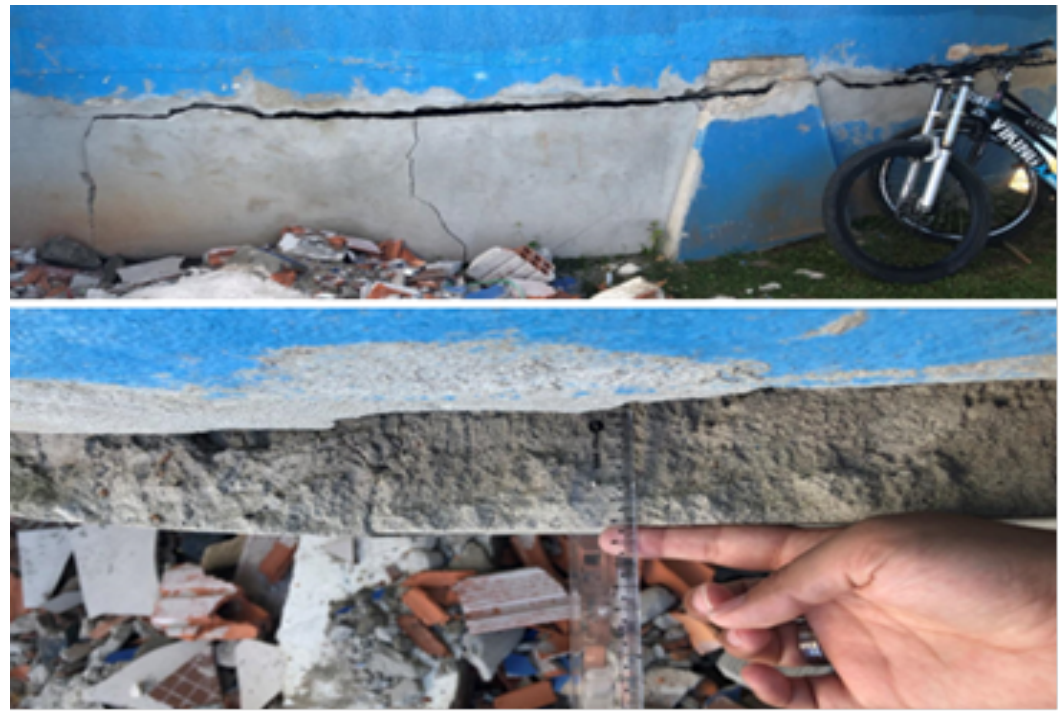

Figura 14: Vista frontal e superior da rachadura abaixo da rampa

Anais do Congresso Brasileiro de Patologia das Construções - CBPAT 2020 
Conforme já mencionado, o talude que contornava toda a escola servia como uma barreira de estabilidade de "máscara", que camuflava os problemas já existentes. Após a retirada do mesmo, a fundação intensificou o processo de recalque, que consequentemente, causou a abertura. Acredita-se que a origem do recalque se deu por erro de dimensionamento (projeto e execução) da fundação e da estrutura, além de infiltração de água, seguida de erosão no solo. E a remoção do talude, além de demonstrar visualmente o processo que já existia, apenas intensificou o mesmo.

Este local foi o que mais sofreu com a ação do recalque da fundação, pois recebe também os carregamentos da rampa, que transporta ações dinâmicas regularmente na estrutura. Dessa forma, quanto mais a fundação sofre de recalque, mais progride a rachadura.

b. Caso 2: Conforme Figura 15, há rachaduras em $45^{\circ}$ que se iniciam no centro da peça e progridem em direção ao apoio e apresentam espessura aproximada de $0,5 \mathrm{~cm}$, além de rachaduras na ligação entre os elementos (rampa e pilar) com aberturas de até $3,5 \mathrm{~cm}$.

As rachaduras de $45^{\circ}$ estão relacionadas às solicitações excessivas na peça, decorrente da carga dinâmica aplicada sob a rampa, que advém da própria movimentação dos alunos. Já as rachaduras na ligação entre o pilar e a rampa se dão devido à falta ou ineficiência de junta de dilatação entre eles. Sem a junta para combater os esforços dos diferentes elementos, a ação do recalque diferencial da fundação influenciou de forma muito acentuada na peça.

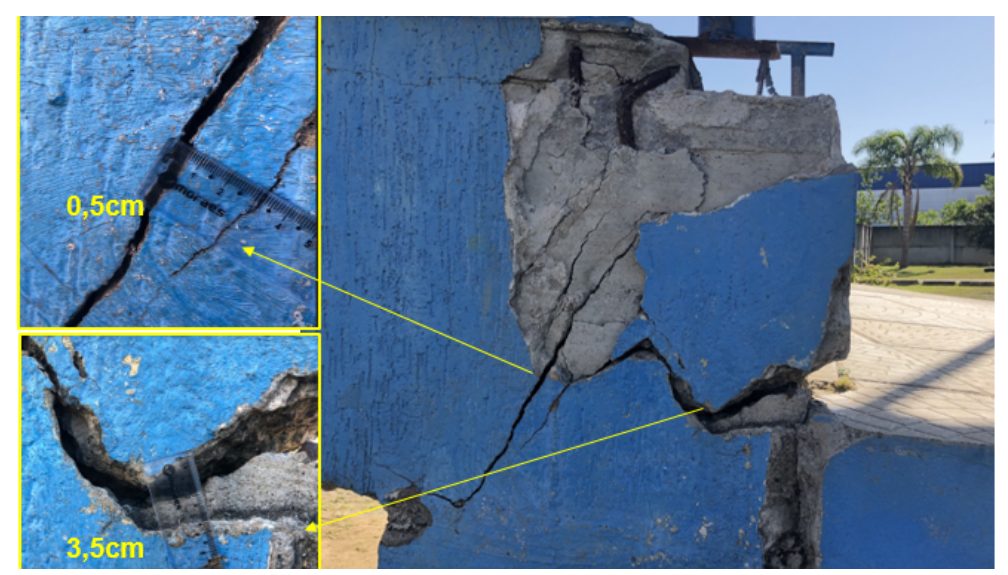

Figura 15: Lateral da rampa com patologia

\subsection{Corrosão}

a. Caso 1: Conforme a Figura 16, a alvenaria está exposta à agentes agressivos e a armadura se encontra em processo de corrosão.

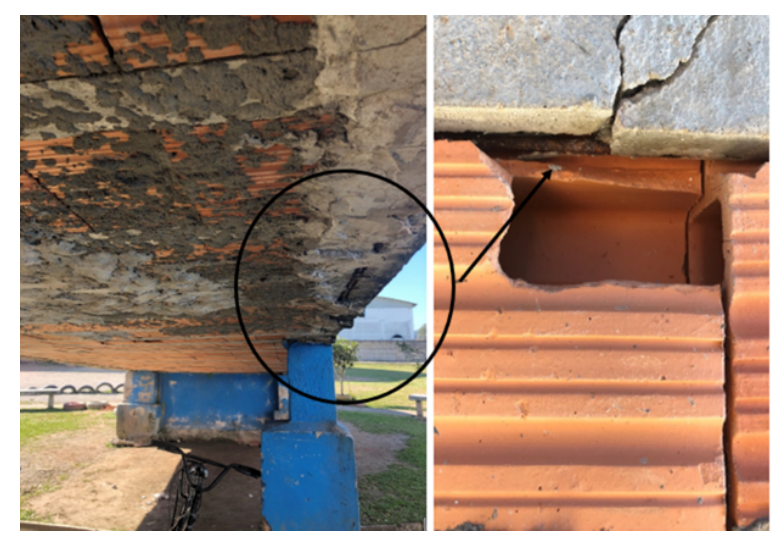

Figura 16 - Armadura exposta

b. Caso 2: Conforme a Figura 17, houve a corrosão da armadura causada por agentes agressivos, resultando no desplacamento do concreto de cobertura. 


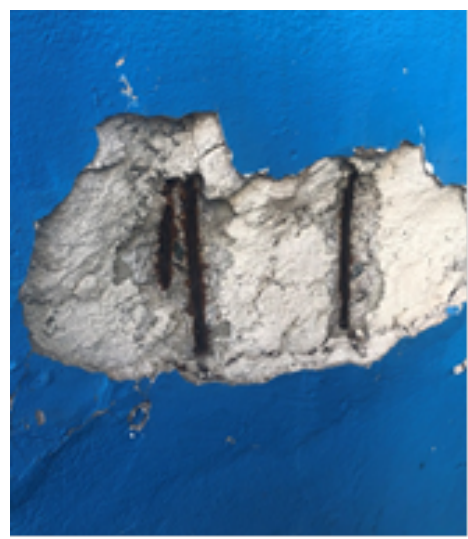

Figura 17: Corrosão de armadura

A corrosão da armadura se dá pela ação química ou eletroquímica do meio ambiente. Nesta edificação, como causas prováveis, pode-se citar a falta de manutenção, defeitos construtivos ou de projeto, cargas atuantes excessivas, ataque de agentes agressivos e a infiltração de oxigênio e umidade, que geram diferença de potencial e causam a corrosão.

\section{ANÁLISE ESTATÍSTICA DE INCIDÊNCIA}

Considerando a incidência de manifestações patológicas em relação às fachadas analisadas, a ocorrência de cada patologia encontra-se no Gráfico 1.

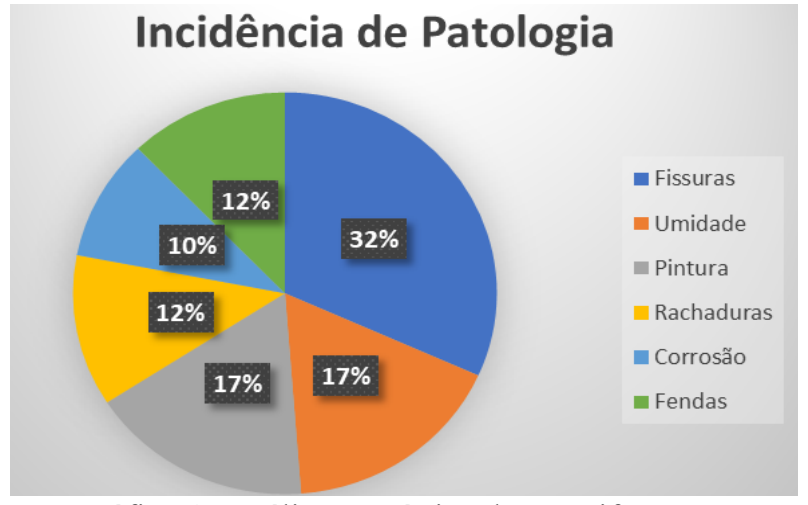

Gráfico 1: Análise estatística das manifestações

Dessa maneira, nota-se que a maior incidência encontrada foi a de fissuras na edificação, com $32 \%$ de ocorrência em toda a escola.

\section{CONCLUSÃO}

A edificação sofre de manifestações patológicas em quase toda sua totalidade, manifestações estas causadas, em sua maioria, devido ao recalque da fundação, que por sua vez, decorre de um mau dimensionamento estrutural, execução não adequada e infiltração de água no interior da edificação.

O talude que existia anteriormente, além de ocultar as anomalias já instaladas na edificação, servia como uma barreira de estabilidade para a estrutura, impedindo a inclinação da mesma. Dessa forma, com a remoção do talude, as manifestações patológicas se expressaram e se intensificaram de forma mais acentuada. E quanto às demais anomalias da edificação, estas estão relacionadas à falta de manutenção, erros executivos e má escolha de materiais.

Isto posto, considerando a progressão das manifestações patológicas, em um curto período de tempo, principalmente se atentada a idade da edificação (relativamente nova), verifica-se a necessidade de intervenção adiantada para a edificação, no que se refere às rachaduras, fendas e físsuras encontradas na edificação. Essa intervenção deve compreender, além dos reparos de correção apontados, um plano de manutenção preventiva, onde tais providências tenham em vista a segurança dos usuários que fazem uso da escola, a conservação da edificação e a prevenção de possíveis anomalias futuras. Tornou- 
se evidente que as alterações executadas na edificação sem o devido acompanhamento técnico, com pouco estudo e análise da situação estrutural da edificação à época, foram as principais origens dos problemas patológicos encontrados.

\section{REFERÊNCIAS}

DAL MOLIN, Denise C. Coitinho. Fissuras em estruturas de concreto armado: Análise das manifestações típicas e levantamento de casos ocorridos no estado do Rio Grande do Sul. Porto Alegre, 1988. Disponível em: < http://hdl.handle.net/10183/15655>. Acesso em 5 dez. 2019.

DUARTE, R.B. Fissuras em alvenaria: causas principais, medidas preventivas e técnicas de recuperação. Porto Alegre, 1998. CIENTEC - $\quad$ Boletim técnico n.25. Disponível em: < http://www.cientec.rs.gov.br/upload/20160728175220boletim_tecnico_25_fissuras_em_alvenarias_causas_principais ,_medidas_preventivas_e_tecnicas_de_recuperacao.pdf >. Acesso em $\overline{5}$ dez. 2019.

GONÇALVES, Eduardo A. Buys. Estudo de patologias e suas causas nas estruturas de concreto armado de obras de edificações. $\quad$ Rio de Janeiro, $2015 . \quad$ Disponível $\quad$ em: $\quad<$ http://monografias.poli.ufrj.br/monografias/monopoli10014879.pdf>. Acesso em 16 dez. 2019.

SANTOS, Altair. Trincas, fissuras, fendas e rachaduras exigem cuidado. Disponível em: <https://www.cimentoitambe.com.br/trincas-fissuras-fendas-e-rachaduras-exigem-cuidado/>. Acesso em: 17 dez. 2019.

SILVA, Isaias Martinez Matias da; SANTOS, Gabriel Dardengo Moraes dos. Levantamento e análise de fissuras em elementos estruturais de concreto armado em edificações no munícipio de Serra - ES. 2018. $20 \mathrm{f}$. Curso de Engenharia Civil, Faculdade Capixaba da Serra - Multivix, Vitória, 2018. Disponível em: <https://multivix.edu.br/wpcontent/uploads/2018/06/levantamento-e-analise-de-fissuras-em-elementos-estruturais-de-concreto-armado-emedificacoes-no-municipio-de-serra-es.pdf>. Acesso em: 6 dez. 2019.

ZANZARINI, José Carlos. Análise das causas e recuperação de fissuras em edificação residencial em alvenaria estrutural - estudo de caso. 2016. 83 f. TCC (Graduação) - Curso de Engenharia Civil, Departamento Acadêmico de Construção Civil, Universidade Tecnológica Federal do Paraná, Campo Mourão, 2016. Disponível em: $<$ http://repositorio.roca.utfpr.edu.br/jspui/bitstream/1/6879/1/CM_COECI_2016_1_15.pdf>. Acesso em: 6 dez. 2019. 